\title{
AIDS-Related Kaposi Sarcoma S1 (Poor Risk)
}

National Cancer Institute

\section{Source}

National Cancer Institute. AIDS-Related Kaposi Sarcoma S1 (Poor Risk). NCI Thesaurus. Code C134983.

AIDS-related Kaposi sarcoma in which systemic illness is present; one or more of the following is true: history of opportunistic infections or thrush; one or more B symptoms is present; Karnofsky performance status score is under 70; other HIV-related illness is present, such as neurological disease or lymphoma. (American Cancer Society) 